\title{
Microbial induced calcite precipitation can consolidate martian and lunar regolith simulants
}

\author{
Rashmi Dikshit ${ }^{1}$, Nitin Gupta ${ }^{1}$, Arjun Dey ${ }^{2}$, Koushik Viswanathan ${ }^{1}$, Aloke Kumar ${ }^{1 *}$ \\ ${ }^{1}$ Department of Mechanical Engineering, Indian Institute of Science, Bangalore 560012 \\ ${ }^{2}$ Thermal Systems Group, U. R. Rao Satellite Centre (Formerly ISRO Satellite Centre), \\ Indian Space Research Organisation, Bangalore, 560017, India \\ *Corresponding author: alokekumar@,iisc.ac.in
}

\begin{abstract}
We demonstrate that Microbial Induced Calcite Precipitation (MICP) can be utilized for creation of consolidates of Martian Simulant Soil (MSS) and Lunar Simulant Soil (LSS) in the form of a 'brick'. A urease producer bacteria, Sporosarcina pasteurii, was used to induce the MICP process for the both simulant soils. An admixture of guar gum as an organic polymer and $\mathrm{NiCl}_{2}$, as bio- catalyst to enhance urease activity, was introduced to increase the compressive strength of the biologically grown bricks. A casting method was utilized for a slurry consisting of the appropriate simulant soil and microbe; the slurry over a few days consolidated in the form of a 'brick' of the desired shape. In case of MSS, maximum strength of 3.3 $\mathrm{MPa}$ was obtained with $10 \mathrm{mM} \mathrm{NiCl}_{2}$ and $1 \%$ guar gum supplementation whereas in case of LSS maximum strength of 5.65 MPa was obtained with $1 \%$ guar gum supplementation and $10 \mathrm{mM} \mathrm{NiCl}_{2}$. MICP mediated consolidation of the simulant soil was confirmed with field emission scanning electron microscopy (FESEM) and X-ray diffraction (XRD). Our work demonstrates a biological approach with an explicit casting method towards manufacturing of consolidated structures using extra-terrestrial regolith simulant; this is a promising route for in situ development of structural elements on the extra-terrestrial habitats.
\end{abstract}

Keywords: Microbially induced calcite precipitation (MICP), Martian Simulant Soil (MSS), Lunar Simulant Soil (LSS), Biocementation, Sporosarcina pasteurii 


\section{INTRODUCTION}

Human curiosity to explore the deep mysteries of space may end up eventually demanding the development of extra-terrestrial settlements. Mars and moon, being close to Earth, have been identified as unprecedented sources of processable materials and have thus become the preferred choices for space organizations around the world to build temporary structures and observatories [1]. On the occasion of the $50^{\text {th }}$ anniversary of manned mission landing on lunar surface, space agencies like the National Aeronautics and Space Administration (NASA) and the European Space Agency (ESA) announced plans to restart manned missions for the exploration of outer space [2-6]. For feasible and sustainable space exploration, these habitats need to be built from available in situ resources on moon/Mars [7-11]. Within space lexicon, the term in situ resource utilization (ISRU) refers to any process that encourages processing of local resources found during exploration of extra-terrestrial habitats in order to reduce dependency on materials chaperoned from Earth. Both martian and lunar surfaces have an abundance of fine soil on their surfaces, termed regolith, which can be utilized as building or raw construction material [1,3]. The primary challenge in this endeavour lies in the consolidation of the unbonded fine regolith particles into a structure of substantial mechanical integrity.

Towards this end, various methodologies for consolidating regolith have been proposed. Fusing of regolith particles through laser-sintering [11], use of microwave irradiation for bonding $[12,13]$ cast basalt production $[9,14-16]$, lunar glass preparation $[17,18]$, sulphurbased concrete preparation $[9,19]$, dry-mix/steam injection methods and various 3D printing methodologies [20-22] are examples of processes that have been proposed. These methods have their own advantages and disadvantages. For instance, laser based sintering of regolith has drawbacks such as high porosity, thermal cracking, and difficulty in casting long blocks. 
$[13,23,24]$. Given the importance and burgeoning interest in extra-terrestrial human settlements, it is necessary that other methods of creating structures from lunar/martian regolith be probed. As a step in this direction, we discuss here a casting method for fabrication of bricklike structures using regolith simulants and a biomineralization process called microbial induced calcite precipitation (MICP).

MICP is a biomineralization process that produces calcium carbonate by exploiting the metabolic activity of bacteria [25-29] via various pathways [30]. The urease pathway is widely explored [31-34] wherein the conditions for mineral precipitation are made favourable by controlled reactions involving hydrolysis of urea by ureolytic bacteria. Urease (E.C. 3.5.1.5), which is a nickel dependent and non-redox enzyme is primarily responsible for urea hydrolysis $[35,36]$. One possible route for enhanced activation of urease activity is by changing the concentration of $\mathrm{Ni}$ (II) ions. Crystal structures of microbial urease enzyme studied from Klebsiella aerogenes [37] and Bacillus pasteurii [38] organisms suggest that it has divalent nickel ion at the centre, which aids in binding the substrate (urea), and alleviates the catalytic transition state thus accelerating the ureolysis reaction rate [39].

In this work we explore this property to enhance the use of MICP based consolidation with martian and lunar regolith. Our study shows a significant increase in the compressive strength of the resulting consolidated brick-like structures with both martian and lunar regolith simulants. The present work also utilizes a naturally occurring and economically viable biopolymer guar gum, to further improve the strength of these bio-consolidated 'space bricks.' Guar gum acts as a stabilizer [26,40] with soil for improving mechanical strength, and is also stable with $\mathrm{pH} /$ temperature variation $[41,42]$ thus making it an ideal additive for MICP mediated space brick formation. For our work, we used the microbe Sporosarcina pasteurii a much explored MICP capable bacteria and a gram positive non-pathogenic strain [29,43-45]. 
In a separate work, we have also designed a modular self-contained lab-on-a-chip (LoC) device for the real time monitoring of the MICP process and demonstrated the survival of this organism under miniaturized experimental environment [46]. We believe that such studies will help evaluate the possibilities of MICP as a sustained solution for building extra-terrestrial settlements utilizing in-situ resources.

\section{MATERIALS AND METHODS}

\subsection{Microorganisms and culture conditions}

Bacterial-induced bio-consolidation was explored using ureolytic bacterial strain; namely, Sporosarcina pasteurii (Miquel) Yoon et al. ATCC ${ }^{\circledR} 11859^{\mathrm{TM}}$, procured from American Type Culture Collection (ATCC) and revived using ATCC recommended media $\left(\mathrm{NH}_{4}\right.$-YE liquid medium).

Flask condition experiments were performed in four different sets as follows:

1. Synthetic media (hereafter, SM); prepared with $0.1 \mathrm{~g}$ glucose, $0.1 \mathrm{~g}$ peptone, $0.5 \mathrm{~g}$ $\mathrm{NaCl}, 0.2 \mathrm{~g}$ mono-potassium phosphate and $3 \mathrm{~g}$ urea in $100 \mathrm{ml}$ of distilled water.

2. Synthetic media-guar gum (hereafter, SM-GG); prepared by replacing glucose in SM medium with 1\%(w/v) guar gum (Urban Platter, India).

3. Synthetic media- $\mathrm{NiCl}_{2}$ (hereafter, $\mathrm{SM}-\mathrm{N}$ ); prepared by adding $10 \mathrm{mM} \mathrm{NiCl}$ in $\mathrm{SM}$ medium.

4. Synthetic media-GG-NiCl 2 (hereafter, SM-GG-N); prepared by adding $10 \mathrm{mM} \mathrm{NiCl} 2$ in SM-GG medium.

Urea was filter sterilized $(0.25 \mu \mathrm{m})$ and added to the medium after autoclaving at $121^{\circ} \mathrm{C}$ and 15 psi for 30 minutes to prevent degradation. Medium was inoculated with $5 \%$ culture of $S$. pasteurii grown up to log phase with 0.8 optical density (OD) and further incubated at $30^{\circ} \mathrm{C}$. Parameters such as OD (using UV/Vis spectrophotometer, Shimadzu, Japan) at $620 \mathrm{~nm}$ 
wavelength, $\mathrm{pH}$ (CyberScan $\mathrm{pH}$ meter, Eutech Instruments) and quantification of ammonium ion concentration using Nessler's reagent assay [33] were recorded at different time intervals. The data was recorded in triplicates and mean value was plotted. All chemicals were procured from Hi-Media, India and used without further purification.

\subsection{Characterization of unconsolidated (raw) soil simulants}

Martian soil simulant (MSS) procured from Class Exolith lab Florida [47], and lunar soil simulant (LSS) developed by the Indian Space Research Organisation (ISRO) [48] were used for the fabrication of the martian and lunar bricks. Particle size distributions for both soil simulants were measured by suspending $0.1 \mathrm{~g}$ soil in $5 \mathrm{ml}$ ultrapure distilled water, followed by sonication to disperse the particles. After sonication, particle suspension was placed on a glass bottom petri dishes (ibid) and imaged using Leica DMI 8 optical microscope (Germany). The images were captured using a Leica DMi8 inverted microscope with Lecia DFC3000G camera and a 10x objective lens. The resulting image resolution was approximately $1 \mu \mathrm{m}$ per pixel. Particle size histograms were obtained using a $50 \mu \mathrm{m}$ bin size. The images were processed using a standard MATLAB ${ }^{\circledR}$ (Mathworks) routine (regionprops) to determine particle dimensions by fitting a horizontally aligned rectangle to each particle [49]. In order to avoid erroneous counting of small insignificant trace particles, the minimum major length of the fit rectangle was selected as 25 pixels $(25 \mu \mathrm{m})$. Particle sizes were obtained from the corresponding rectangles as the radii of equivalent circles with the same area. Correspondingly, the minimum equivalent diameter for LSS was $7.44 \mu \mathrm{m}$ and for MSS particles was $6.62 \mu \mathrm{m}$.

\subsection{Casting process for repeatable and scalable sample preparation}

In lieu of a conventional bioreactor, for the present work we designed and used aluminium molds to cast bricks of uniform size and shape, in a repeatable and scalable manner. The molds were made of aluminium alloy (A16061-T6), machined using a vertical milling machine. Each 
mold was made in two mating parts, to enable easy casting and parting off, and consisted of five cuboidal cavities with a cross section of $32 \times 32 \mathrm{~mm}^{2}$ and a height of $35 \mathrm{~mm}$. Thus a single two-part mould could be used to cast five samples simultaneously. A schematic representation of this casting process for MICP mediated consolidation is depicted in Figure 1 and representative image of these consolidated samples, which we have termed 'space bricks', are given in the Figure 2. The inner surface of the mold was covered with a thin transparent plastic (OHP) sheet to aid easy removal of consolidated samples from the mold. Fifty grams of autoclaved simulant soil (at $121^{\circ} \mathrm{C}$ and 15 psi for 30 minutes) were mixed with media and various combinations of treatments as presented in Table 1, and discussed in Sec. 2.1. S. pasteurii with optical density at $620 \mathrm{~nm}\left(\mathrm{OD}_{620}\right) 1.5$ in $\mathrm{NH}_{4}$-YE medium was used as inoculum in all the treatments. The soil-bacteria-medium mixture was tightly packed in the mold cavities and the upper part of the mold was sealed with parafilm strip, see Fig.1c. Incubation period was set for 5 days at $32^{\circ} \mathrm{C}$ followed by drying in a hot air oven (BioBee, India) at $50^{\circ} \mathrm{C}$ for a period of $24 \mathrm{~h}$.

Table 1. Different treatments used in experiment for bio-consolidation of lunar (LSS) and martian (MSS) soil simulants

\begin{tabular}{|c|c|c|c|c|c|}
\hline Name & $\begin{array}{c}\text { Bacterial } \\
\text { Strain }\end{array}$ & $\begin{array}{c}\text { Precipitation } \\
\text { Media }\end{array}$ & $\begin{array}{c}\text { Calcium } \\
\text { Lactate } \\
50 \mathrm{mM}\end{array}$ & $\begin{array}{c}\text { Guar Gum } \\
(\% \text { W/W) }\end{array}$ & $\begin{array}{l}\mathrm{NiCl}_{2} \\
(\mathbf{m M})\end{array}$ \\
\hline MSS-SP & S. pasteurii & SMU & Yes & 0 & 0 \\
\hline MSS-SP-GG & S. pasteurii & SMU & Yes & 1 & 0 \\
\hline MSS-SP-N & S. pasteurii & SMU & Yes & 0 & 10 \\
\hline MSS-SP-GG-N & S. pasteurii & SMU & Yes & 1 & 10 \\
\hline LSS-SP & S.pasteurii & SMU & Yes & 0 & 0 \\
\hline LSS-SP-GG & S. pasteurii & SMU & Yes & 1 & 0 \\
\hline LSS-SP-N & S. pasteurii & SMU & Yes & 0 & 10 \\
\hline LSS-SP-GG-N & S. pasteurii & SMU & Yes & 1 & 10 \\
\hline
\end{tabular}

\subsection{Mechanical and Materials Characterizations}


Compression testing of consolidated MSS and LSS samples was carried out on a Universal Testing Machine (Instron-5697), with a $5 \mathrm{kN}$ capacity load cell and loading rate of $1 \mathrm{~mm} / \mathrm{min}$. To ensure uniform compression during the test, all surfaces of the cubical samples were ground and polished using a portable grinder (BOSCH GWS 600). The final specimen for testing was in the form of a cube with dimensions $25 \pm 2 \mathrm{~mm}$. A minimum of three test specimens were made for each set of treatments, and the average value of the data was plotted. All samples were tested in same condition except for MSS-SP-N and MSS-SP-GG-N. In the latter two cases, $2 \mathrm{~mm}$ rubber sheets were used between the sample surface and the UTM grips to uniformly distribute the load across the sample surface. This was because making perfectly flat samples for these two conditions proved to be extremely challenging, even after multiple grinding and polishing attempts. Furthermore, given the nonuniform nature of consolidated soil samples in general, the measured stress-strain curves contained a few small intermediate peaks. Peaks with a maximum peak/valley distance of less than $6 \%$ of the overall load maximum were not considered to points of failure, whereas the first peak larger than this $6 \%$ threshold was taken to be the point of failure.

The microstructure of bio-consolidated martian and lunar bricks was observed using field emission scanning electron microscopy (FESEM:_Carl Zeiss AG - ULTRA 55, Germany). Different calcium carbonate phases were identified using a X-ray diffractometer (XRD: PANalytical Philips diffractometer, Rigaku SmartLab, Rigaku Corporation) under $\mathrm{Cu}-\mathrm{K} \alpha(\lambda=$ $1.54 \AA$ ) X-ray radiation and thoroughly indexed as per Inorganic Crystal Structure Database (ICSD) library using PANalytical X'Pert High Score Plus pattern analysis software.

\section{RESULTS AND DISCUSSIONS}

Lunar and martian soil/regolith simulants used in this experiment were drawn from two different sources and their mineral composition/particle size distribution was first established. 


\subsection{Lunar and martian soil simulants: Composition and particle properties}

Figure 3 depicts the size and morphological characterization for MSS and LSS particles. Figure 3a,b show the size histogram for MSS and LSS particles, respectively, with insets showing corresponding representative FESEM images. The mean particle diameter for LSS particles was approximately $34 \mu \mathrm{m}$ with a standard deviation of $26 \mu \mathrm{m}$, while corresponding numbers for MSS were $31 \mu \mathrm{m}$ and $33 \mu \mathrm{m}$, respectively. This indicates that that MSS typically contains a wider distribution of particle sizes than LSS. However, in both cases, particles were observed to be irregularly shaped. The particle aspect ratio, determined as discussed in Sec. 2.3, quantifies this irregularity; aspect ratios for MSS and LSS particles were around 0.5 and 0.56, respectively.

In order to identify the phases and the elements present in both soil simulants, XRD and energy dispersive spectroscopy (EDS) were performed, see Fig. 4. In MSS, plagioclase, pyroxene and olivine (Fig. 4 (a)) were identified as prime crystalline phases whereas in LSS, plagioclase (Fig. 4 (b)) was the major crystalline phase. MSS possesses significant amount of pyroxene (XY $\left.(\mathrm{Si}, \mathrm{Al})_{2} \mathrm{O}_{6}\right)$, that contains $\mathrm{Mg}$ and $\mathrm{Fe}$ along with $\mathrm{Si}$ and aluminium oxide. Correspondingly, major elements observed in MSS from EDS mapping were $\mathrm{O}, \mathrm{Si}, \mathrm{Al}, \mathrm{Mg}$ and $\mathrm{Fe}$ as shown in Figure 4 (c). Fe and $\mathrm{Mg}$ are essential metal ions required in limited concentration for bacterial growth. It is well known that $\mathrm{Mg}$ is important for cell division of the rod-shaped bacteria whereas iron contributes in biological activity such as electron transfer and enzymatic activity [50]. Incidentally, iron appears in two oxidation states viz. $\mathrm{Fe}^{2+}$ and $\mathrm{Fe}^{3+}$ in the bacterial cells that can be transformed into each other. Though these ions are essential for bacterial growth and activity, their requirement is very low. It is reported that higher concentrations of iron may lead to toxic effects on bacterial cells due to generation of reactive oxygen compounds [51]. This may cause peroxidation of lipids cell membrane, protein and can also damage cellular DNA. [52]. The relevance of these observations will be discussed subsequently when 
consolidation results of MSS and LSS are discussed. In the case of LSS, the major mineral identified was plagioclase, composed of $\mathrm{NaAlSi}_{3} \mathrm{O}_{8}$ and $\mathrm{CaAl}_{2} \mathrm{Si}_{2} \mathrm{O}_{8}$ and containing $\mathrm{Si}, \mathrm{Al}, \mathrm{Na}$ and $\mathrm{Ca}$ elements. These elements were, consequently, also detected in the EDS maps presented in Fig. 4(d).

\subsection{MICP induced consolidation of martian regolith}

The molding/casting process adopted here allows us to make various shapes and even hollow structures that are simply not possible in a conventional bioreactor. For the purpose of determining the optimal process parameters, a mixture of microbial culture and regolith were pre-mixed in slurry form and incubated in the mold cavities for a period of about 5 days. At the end of the process, these cubical samples were retrieved, dried and subjected to quasi-static compression tests, as described in Sec. 2.3. Figure 5a shows the results of compressive strength measurement on various slurries containing different media combinations. MSS slurries mixed with only S. pasteurii or SP culture, when retrieved and dried, were not robust enough for uniaxial testing so data corresponding to this medium (MSS-SP) is not included in Fig. 5a. Non-consolidation of MSS is probably due to the presence of approximate $12 \% \mathrm{Mg}$ and $6.9 \%$ iron causing inhibition of urease activity of $S$. pasteurii in absence of additives. Supplementing the MSS slurry with 1\% guar gum resulted in mean compressive strength of approximately 1.1 MPa, see MSS-SP-GG bar in Fig. 5a.

Since the urease enzyme is a metalloenzyme containing nickel at the centre $[39,53]$, potential enhancement of urease activity via Ni supplementation was evaluated next. Flask growth data suggested that $10 \mathrm{mM}$ of $\mathrm{Ni}$ supplementation can enhance urease activity significantly and thereby accelerate the overall MICP process (data not shown). The mean compressive strength of the consolidated brick sample obtained by $10 \mathrm{mM} \mathrm{NiCl}_{2}$ supplementation (MSS-SP-N) was found approximately 2.67 MPa. Hence, the strength was consistently found to be twice as large 
as that of the MSS-SP-GG consolidated samples. Subsequently it was deemed natural to evaluate the compressive strength of consolidated samples with both guar gum (GG) as well as Nickel supplementation. The MSS supplemented with $1 \%$ guar gum and $10 \mathrm{mM}$ Nickel (MSS-SP-GG -N) showed a significantly larger mean compressive strength, of 3.3 MPa, which was the largest among all the treatments, see Fig. 5(a). It is hence clear that the addition of guar gum and Ni results in significantly stronger consolidates, approaching the compressive strength of ice.

Structural changes arising in consolidated MSS due to MICP were by XRD analysis and supported by FESEM imaging presented in Figure 5 (b, c \& d). The XRD patterns for the three different treatments (MSS-SP-N, MSS-SP-GG and MSS-SP-GG-N) discussed above are presented in Fig. 5b. It is clear that several calcium carbonate phases (e.g., calcite, aragonite and vaterite) of precipitates are observed in all three cases. In case of MSS-SP-GG-N treatment, the peaks correspond to the calcite phase at $2 \theta$ values of $23.01^{\circ}, 35.50^{\circ}, 62.7^{\circ}, 65.1^{\circ}(\mathrm{hkl}$ value 012, 111, 212, 122) matched with ICSD File nos. 98-000-5337, 98-001-442 respectively whereas peaks at $2 \theta$ values of $20.8^{\circ}, 52.32^{\circ}$ (ICSD File no. 98-010-9796) were observed for vaterite phase. Aragonite phase matching with ICSD File no. -98-011-4648 was also observed at $2 \theta$ values of $67.42^{\circ}$. In MSS-SP-N treatment major peaks at $2 \theta$ values $29.3^{\circ}, 42.5^{\circ}$ for calcite phase with hkl $(101,002)$ matched with ICSD File no. 98-001-4421. Major identified peaks in MSS-SP-GG treatments were at $2 \theta$ values $62.7^{\circ}$ matching with ICSD File no. $98-001-4421$ for calcite phase of calcium carbonate. As expected, treatment without any additives (MSS-SP) did not show any significant calcium carbonate peaks indicating inhibition of MICP activity and, consequently, poor strength of the consolidated sample.

The FESEM micrograph of bio-consolidated MSS bricks also clearly showdepicted bacterial mediated consolidation. An aggregated soil mass with appreciable bacterial induced 
precipitates were seen in MSS-SP-GG-N treatment (Figure 5c) whereas in the case of MSSSP-GG treatment bacterial induced covering on the soil mass was observed (Fig. 5d).

\subsection{MICP induced consolidation of lunar regolith}

An analogous procedure was followed the the lunar soil simulant (LSS) and the results are summarized in Fig. 6. Similar to the MSS slurry treatments, supplementation with both $1 \%$ guar gum and $10 \mathrm{mM} \mathrm{NiCl}_{2}$ resulted in bricks with the maximum compressive strength, see Fig. 6. Furthermore, guar gum and Ni supplemented LSS samples (LSS-SP-GG-N) showed mean compressive strength of $5.65 \mathrm{MPa}$, which was significantly higher than the corresponding value for MSS-SP-GG-N. Additionally, LSS consolidation using a slurry with just the microbial medium (LSS-SP) was found to be robust enough to be subjected to uniaxial testing, with a resulting mean compressive strength of $0.75 \mathrm{MPa}$. When using only guar gum supplement (LSS-SP-GG), mean compressive strength of 3.41MPa was obtained.

These results seem to suggest that MSS provides a less ideal environment for bacterial growth as compared to LSS primarily due to the existence of metals such as $\mathrm{Fe}$ and $\mathrm{Mg}$ in significantly higher quantities. An additional difference between the consolidated LSS and MSS bricks is that LSS-SP-GG samples showed higher mean compressive strength compared to LSS-SP-N samples. The reason for this difference is at present not well understood and requires further investigation.

XRD analysis of lunar bricks showed multiple calcium carbonate peaks, as expected, thus confirming bio-consolidation (Fig. 6 (b)). The major identified peaks in the treatment of LSSSP-N corresponding to the calcite phases were found at $2 \theta$ values $23.02^{\circ}(\mathrm{hkl} 012), 29.40^{\circ}(\mathrm{hkl}$ 104), $35.9^{\circ}$ (hkl 110) and 47.0 (hkl 018) and matched with ICSD File nos. 00-005-0586. In the case of LSS-SP-GG-N, identified phases of calcite were at $2 \theta$ values $29.3^{\circ}$ (hkl104), $35.40^{\circ}$ (hkl 110), $42.01^{\circ}(\mathrm{hkl} 200)$, matched with ICSD File nos. 00-005-0586,980005339 and 98-0114421 respectively, whereas for vaterite phase at $2 \theta$ values $45.6^{\circ}(301), 49.6^{\circ}(\mathrm{hkl} 412), 53.7^{\circ}$ 
(hk1 222) and matched with ICSD File nos. 98-010-9797.The peaks correspond to the calcite phase at $2 \theta$ values of $24.60^{\circ}(\mathrm{hkl} 111), 31.50^{\circ}$ (hkl 202) matched with ICSD File nos. 98-007-

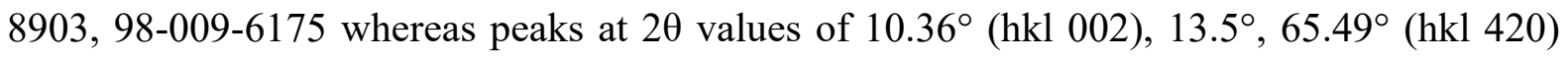
(ICSD File nos. 98-000-6092, 98-010-9797, 98-010-9796) was observed for vaterite phase. Aragonite phase matched with ICSD File nos. - 98-011-4648, 98-011-4649 was also observed at $2 \theta$ values of $57.71^{\circ}$ with hkl 122 in case of LSS-SP-GG treatment.

Just as with the consolidated MSS bricks, aggregard soil masses were also observed in the case of the LSS bricks, see FESEM micrographs in Figs .6c and 6d. In the case of guar gum supplement, dense aggregated soil mass was observed (Fig 5c) while bacterial induced matrix and precipitates covering the LSS particle were observed in the treatment with $1 \%$ guar gum and $10 \mathrm{mM}$ Nickel admixture (Fig. 6d).

\subsection{Flask-condition evaluation of additives}

The XRD and microstructural data of consolidated LSS and MSS bricks clearly confirm bacterial induced consolidation in both soil simulants. Peaks representing different phases of calcium carbonate (calcite, aragonite and vaterite) in MSS-SP-N and MSS-SP-GG-N for MSS and in LSS-SP-GG and LSS-SP-GG-N for LSS clearly show the occurrence of bacterial mediated bio-consolidation of martian and lunar bricks. These results serve to demonstrate that supplementation with guar gum and Ni can significantly enhance urease activity in both soil simulants, thereby accelerating the MICP process and leading to considerable increase in compressive strength.

The biological origins of the increase in compressive strength with $\mathrm{NiCl}_{2}$, and guar gum separately, as well as together, were explored by performing physiological studies on the bacterial strain covering the primary parameters with respect to the ureolytic pathway. Figure 7 shows the change in medium $\mathrm{pH}$, ammonium ion concentration and its effect on bacterial 
growth for these treatments. Typical lag, log, stationery and death phases of bacterial growth pattern can be seen clearly with and without guar gum and $\mathrm{NiCl}_{2}$ additives (Fig $7 \mathrm{a}$ ). The lag phase (where bacteria is prepared for multiplication) and the log phase (where the bacteria actually multiply) of bacterial growth were observed to be comparatively longer with SM-GG, and SM-GG-N treatments where guar gum served as the sole carbon source. The lag phase for SM-GG lasted for 6 hours of incubation, as against 2 hours for SM and SM-N treatment. Interestingly, the log phase was almost 1.5 times longer for treatments with guar gum supplementation in both cases with and without Ni suplementation. The stationary phase (i.e., where cell division and death rate become equal) was smaller and well defined for treatments without guar gum supplementation whereas with guar gum supplementation the stationary phase continued till the end of the experiment duration thus demonstrating sustainability of bacteria.

The supplementation of $\mathrm{Ni}$ in the media gave noteworthy results irrespective of the guar gum supplementation. There is a distinct shift seen with Nickel supplementation in the graph for ammonium ion concentration (in SM-N and SM-GG-N treatments as compared to SM and SMGG treatments). The slope of the plot showed an increase with or without guar gum supplementation depicting an acceleration in the bacterial biochemical process. An increase in ammonium ion concentration was also recorded at the end of the log phase of bacterial growth in these treatments resulting in an incremental shift in the $\mathrm{pH}$ (inset image of Fig. 7b) of the medium. The supplementation of Nickel increased the ammonium ion concentration values approximately 1.7 times with increase in basicity of the media (Fig. 7b). However, the maximum urease activity was observed with the combination of both the additives (SM-GG-N treatment) exploiting their cumulative benefits and thus validating the results obtained for the compressive strength of both the simulants.

\section{CONCLUSIONS}


We have shown that bacteria-mediated MICP technique can efficiently consolidate lunar and martian regolith simulant into brick-like structures with promising structural strength. These brick-like structures have been christended 'space-bricks'[40]. Further, we have also presented a casting method, which can be ideal for making various shape structures as well as bricks with consistent strength. A natural polymer (guar gum) as an additive and appropriate concentration of $\mathrm{NiCl}_{2}$ tend to accelerates the overall MICP process thus contributing towards enhancing the strength of the space bricks. Hence this biological approach, coupled with a scalable casting method, towards manufacturing of bricks presents a promising and highly sustainable potential route for in situ utilization of structural elements on extra-terrestrial habitats.

\section{Acknowledgments}

RD acknowledges funding from Department of Biotechnology, Ministry of Science and Technology, GOI for their grant under BioCare scheme (BT/PR31844/BIC/101/1206/2019). Authors acknowledge thank Indian Space Research Organisation for providing the lunar soil simulant. We thank Dr. Amrit Ambirajan, Research Professor, IISc and former Scientist, ISRO for stimulating discussions and for suggesting the name 'space bricks'.

\section{REFERENCES}

1. Bogdahn C, Breaum A, Breum H, Larsen H, Løvenskjold M, Kristiansen T-H. In-situ Habitat Design on Mars. 2019.

2. DUST OFC, CORAZZARI I, DURANTE M, FUBINI B, GERDE PER, KARLSSON LL, et al. HISTORY AND FUTURE PERSPECTIVES.

3. Naser MZ. Extraterrestrial construction materials. Prog Mater Sci. 2019;105: 100577.

4.

NASAhttps://www.nasa.gov/sites/default/files/atoms/files/america_to_the_moon_202 
4_09-16-2019.pdf. No Title.

5. Stern A. Commercial space flight is a game-changer. Nat News. 2012;484: 417.

6. Seedhouse E. Red Dragons, Ice Dragons, and the Mars Colonial Transporter. SpaceX's

Dragon: America’s Next Generation Spacecraft. Springer; 2016. pp. 145-162.

7. Wilhelm S, Curbach M. Review of possible mineral materials and production techniques for a building material on the moon. Struct Concr. 2014;15: 419-428. doi:10.1002/suco.201300088

8. David CW. Particle Size Distribution of Lunar Soil. J Geotech Geoenvironmental Eng. 2003;129: 956-959. doi:10.1061/(ASCE)1090-0241(2003)129:10(956)

9. Happel JA. Indigenous materials for lunar construction. 1993.

10. Anand M, Crawford IA, Balat-Pichelin M, Abanades S, van Westrenen W, Péraudeau $\mathrm{G}$, et al. A brief review of chemical and mineralogical resources on the Moon and likely initial in situ resource utilization (ISRU) applications. Planet Space Sci. 2012;74: 42-48. doi:https://doi.org/10.1016/j.pss.2012.08.012

11. Faierson EJ, Logan K V. Potential ISRU of lunar regolith for planetary habitation applications. Moon. Springer; 2012. pp. 201-234.

12. Cliffton EW. A fused regolith structure. Engineering, construction, and operations in space II. ASCE; 1990. pp. 541-550.

13. Taylor LA, Meek TT. Microwave sintering of lunar soil: properties, theory, and practice. J Aerosp Eng. 2005;18: 188-196.

14. Greene KA. Design Note on Post-Tensioned Cast Basalt. Engineering, construction, and operations in challenging environments: Earth and space 2004. 2004. pp. 45-50.

15. Binder AB, Culp MA, Toups LD. Lunar derived construction materials: Cast basalt. Engineering, construction, and operations in space II. ASCE; 1990. pp. 117-122.

16. Happel JA, Willam K, Shing B. Design concepts for pressurized lunar shelters 
utilizing indigenous materials. 1991.

17. Allen DD, Poisl WH, Fabes BD. Strength and fracture of glass in the lunar environment. 1992.

18. Allen CC, Hines JA, McKay DS, Morris R V. Sintering of lunar glass and basalt. Engineering, Construction, and Operations in space-III: Space’92. 1992. pp. 12091218.

19. Leonard RS, Johnson SW. Sulfur-based construction materials for lunar construction. Engineering, construction, and operations in space. ASCE; 1988. pp. 1295-1307.

20. Leach N, Carlson A, Khoshnevis B, Thangavelu M. Robotic construction by contour crafting: The case of lunar construction. Int J Archit Comput. 2012;10: 423-438.

21. Cesaretti G, Dini E, De Kestelier X, Colla V, Pambaguian L. Building components for an outpost on the Lunar soil by means of a novel 3D printing technology. Acta Astronaut. 2014;93: 430-450.

22. Khoshnevis B, Carlson A, Leach N, Thangavelu M. Contour crafting simulation plan for lunar settlement infrastructure buildup. Earth and Space 2012: Engineering, Science, Construction, and Operations in Challenging Environments. 2012. pp. 14581467.

23. Vamsi KB. First demonstration on direct laser fabrication of lunar regolith parts. B. RL, editor. Rapid Prototyp J. 2012;18: 451-457. doi:10.1108/13552541211271992

24. Crockett RS, Fabes BD, Nakamura T, Senior CL. Construction of large lunar structures by fusion welding of sintered regolith. Engineering, construction, and operations in space IV. ASCE; 1994. pp. 1116-1127.

25. Ghosh T, Bhaduri S, Montemagno C, Kumar A. Sporosarcina pasteurii can form nanoscale calcium carbonate crystals on cell surface. PLoS One. 2019;14: e0210339. Available: https://doi.org/10.1371/journal.pone.0210339 
26. Dikshit R, Jain A, Dey A, Kumar A. Microbially induced calcite precipitation using Bacillus velezensis with guar gum. PLoS One. 2020. doi:10.1371/journal.pone.0236745;[EMID:4a648f54ea733dbd]

27. Tiano P, Biagiotti L, Mastromei G. Bacterial bio-mediated calcite precipitation for monumental stones conservation: methods of evaluation. J Microbiol Methods. 1999;36: 139-145.

28. Reddy MS. Biomineralization of calcium carbonates and their engineered applications: a review. Front Microbiol. 2013;4: 314.

29. Achal V, Mukherjee A, Basu PC, Reddy MS. Strain improvement of Sporosarcina pasteurii for enhanced urease and calcite production. J Ind Microbiol Biotechnol. 2009;36: 981-988.

30. Anbu P, Kang C-H, Shin Y-J, So J-S. Formations of calcium carbonate minerals by bacteria and its multiple applications. Springerplus. 2016;5: 250.

31. Fujita Y, Ferris FG, Lawson RD, Colwell FS, Smith RW. Subscribed Content Calcium Carbonate Precipitation by Ureolytic Subsurface Bacteria. Geomicrobiol J. 2000;17: 305-318. doi:10.1080/782198884

32. Castanier S, Le Métayer-Levrel G, Orial G, Loubière J-F, Perthuisot J-P. Bacterial carbonatogenesis and applications to preservation and restoration of historic property. Of microbes and art. Springer; 2000. pp. 203-218.

33. Cuzman OA, Richter K, Wittig L, Tiano P. Alternative nutrient sources for biotechnological use of Sporosarcina pasteurii. World J Microbiol Biotechnol. 2015;31: 897-906.

34. Randall DG, Naidoo V. Urine: The liquid gold of wastewater. J Environ Chem Eng. 2018;6: 2627-2635. doi:https://doi.org/10.1016/j.jece.2018.04.012

35. Benini S, Cianci M, Mazzei L, Ciurli S. Fluoride inhibition of Sporosarcina pasteurii 
urease: structure and thermodynamics. JBIC J Biol Inorg Chem. 2014;19: 1243-1261.

36. Maroney MJ, Ciurli S. Nonredox nickel enzymes. Chem Rev. 2014;114: 4206-4228.

37. Jabri E, Carr MB, Hausinger RP, Karplus PA. The crystal structure of urease from Klebsiella aerogenes. Science (80- ). 1995;268: 998-1004.

38. Benini S, Rypniewski WR, Wilson KS, Miletti S, Ciurli S, Mangani S. A new proposal for urease mechanism based on the crystal structures of the native and inhibited enzyme from Bacillus pasteurii: why urea hydrolysis costs two nickels. Structure. 1999; 7: 205-216.

39. Krajewska B. Ureases I. Functional, catalytic and kinetic properties: A review. J Mol Catal B Enzym. 2009;59: 9-21.

40. Dikshit R, Dey A, Gupta N, Varma SC, Venugopal I, Viswanathan K, et al. Space bricks: From LSS to machinable structures via MICP. Ceram Int. 2021;47: 1489214898.

41. Mudgil D, Barak S, Khatkar BS. Guar gum: processing, properties and food applications - a review. J Food Sci Technol. 2014;51: 409-418.

42. Muguda S, Booth SJ, Hughes PN, Augarde CE, Perlot C, Bruno AW, et al. Mechanical properties of biopolymer-stabilised soil-based construction materials. Géotechnique Lett. 2017; 7: 309-314.

43. Stocks-Fischer S, Galinat JK, Bang SS. Microbiological precipitation of CaCO3. Soil Biol Biochem. 1999;31: 1563-1571.

44. Lambert SE, Randall DG. Manufacturing bio-bricks using microbial induced calcium carbonate precipitation and human urine. Water Res. 2019;160: 158-166. doi:https://doi.org/10.1016/j.watres.2019.05.069

45. Bhaduri S, Debnath N, Mitra S, Liu Y, Kumar A. Microbiologically induced calcite precipitation mediated by Sporosarcina pasteurii. JoVE (Journal Vis Exp. 2016; 
e53253.

46. Kallapur S, Dikshit R, Dey A, Nandi A, Singh V, Viswanathan K, et al. Microbial analysis in space: Modular device for biological experiments in microgravity. Acta Astronaut. 2021.

47. Cannon KM, Britt DT, Smith TM, Fritsche RF, Batcheldor D. Mars global simulant MGS-1: A Rocknest-based open standard for basaltic martian regolith simulants. Icarus. 2019;317: 470-478.

48. Venugopal I, Muthukkumaran K, Annadurai M, Prabu T, Anbazhagan S. Study on geomechanical properties of lunar soil simulant (LSS-ISAC-1) for chandrayaan mission. Adv Sp Res. 2020;66: 2711-2721.

49. Mathworks C. Image Processing Toolbox User’s Guide R2014b. 2014; 664.

50. Sritharan M. Iron as a candidate in virulence and pathogenesis in mycobacteria and other microorganisms. World J Microbiol Biotechnol. 2000;16: 769-780.

51. Storz G, Imlayt JA. Oxidative stress. Curr Opin Microbiol. 1999;2: 188-194.

52. Sorokina E V, Yudina TP, Bubnov IA, Danilov VS. Assessment of iron toxicity using a luminescent bacterial test with an Escherichia coli recombinant strain. Microbiology. 2013;82: 439-444.

53. Kaminskaia N V, Kostić NM. Kinetics and Mechanism of Urea Hydrolysis Catalyzed by Palladium(II) Complexes. Inorg Chem. 1997;36: 5917-5926. doi:10.1021/ic961500p 


\section{Figure and captions}
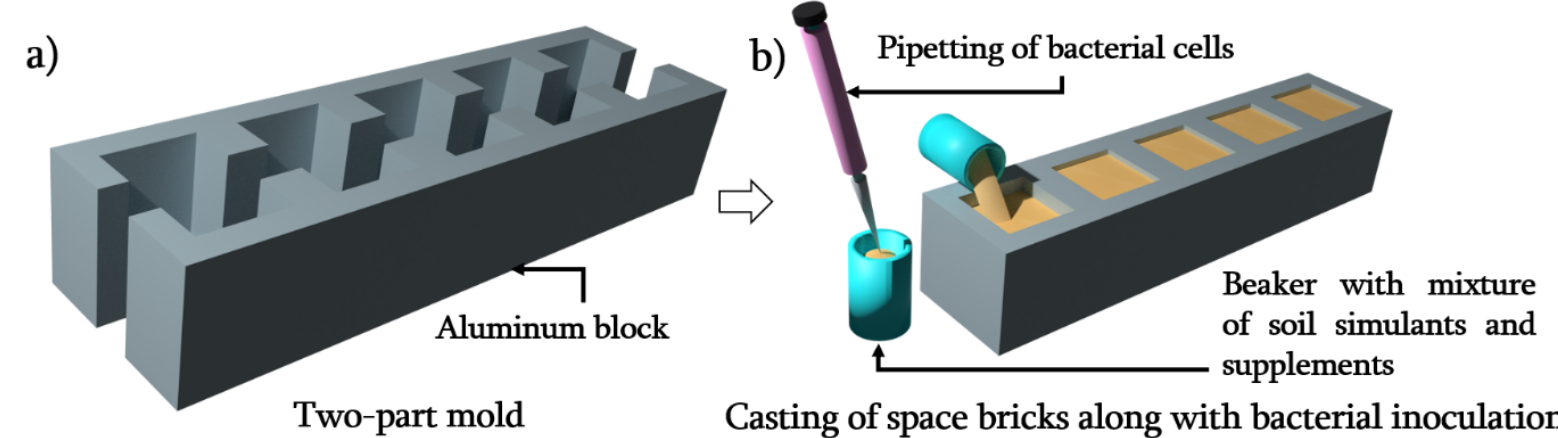

Casting of space bricks along with bacterial inoculation

d)

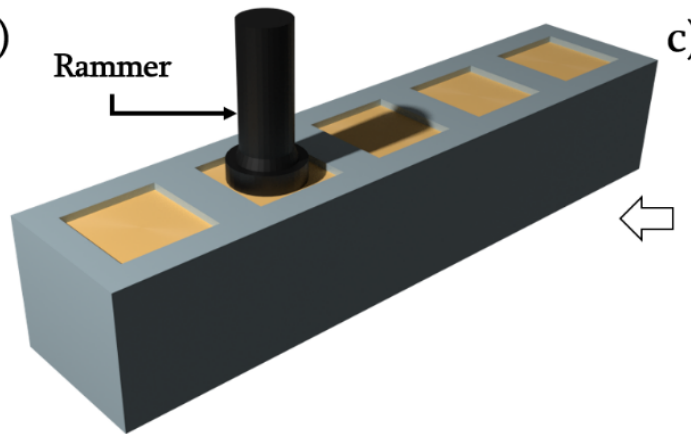

Pressing of consolidate after 5 days c)

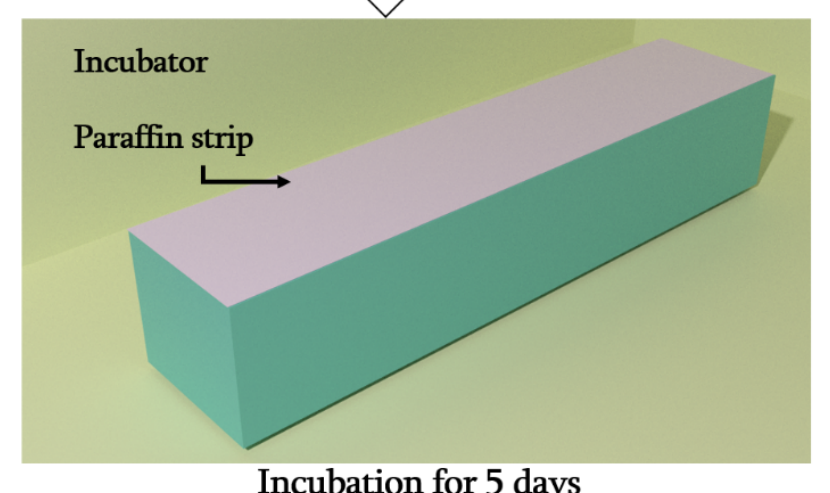

Incubation for 5 days

Fig:1: Schematic representation of casting of aluminium mould and process involved in MICP mediated consolidation of simulant soils.

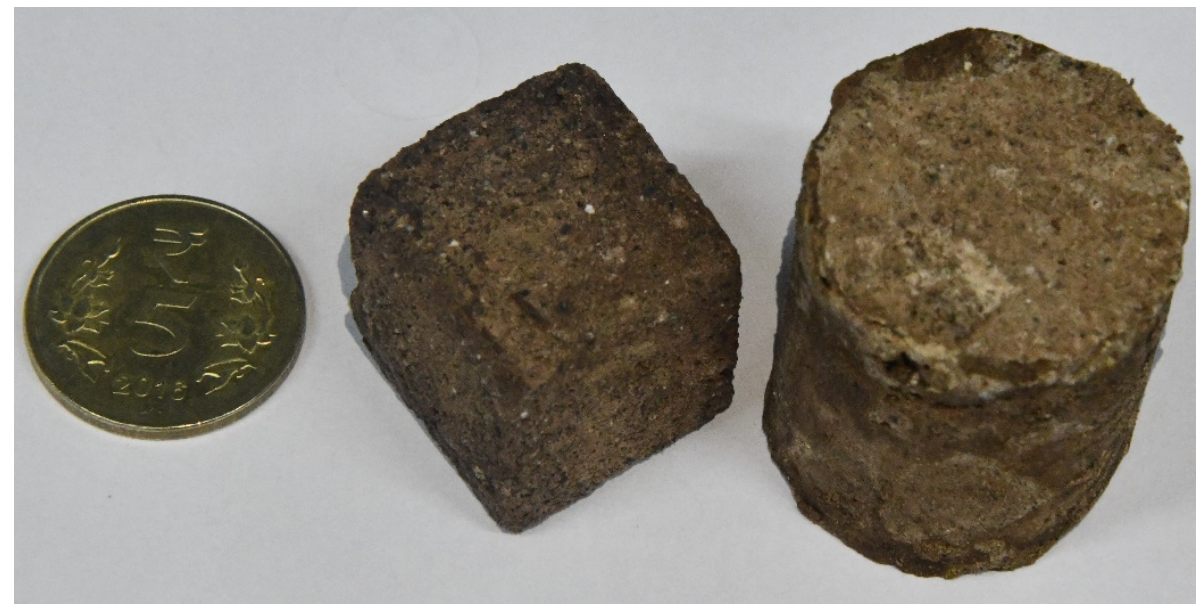

Fig: 2 Representative image of consolidated samples using MSS. Such structures have been termed space bricks. 

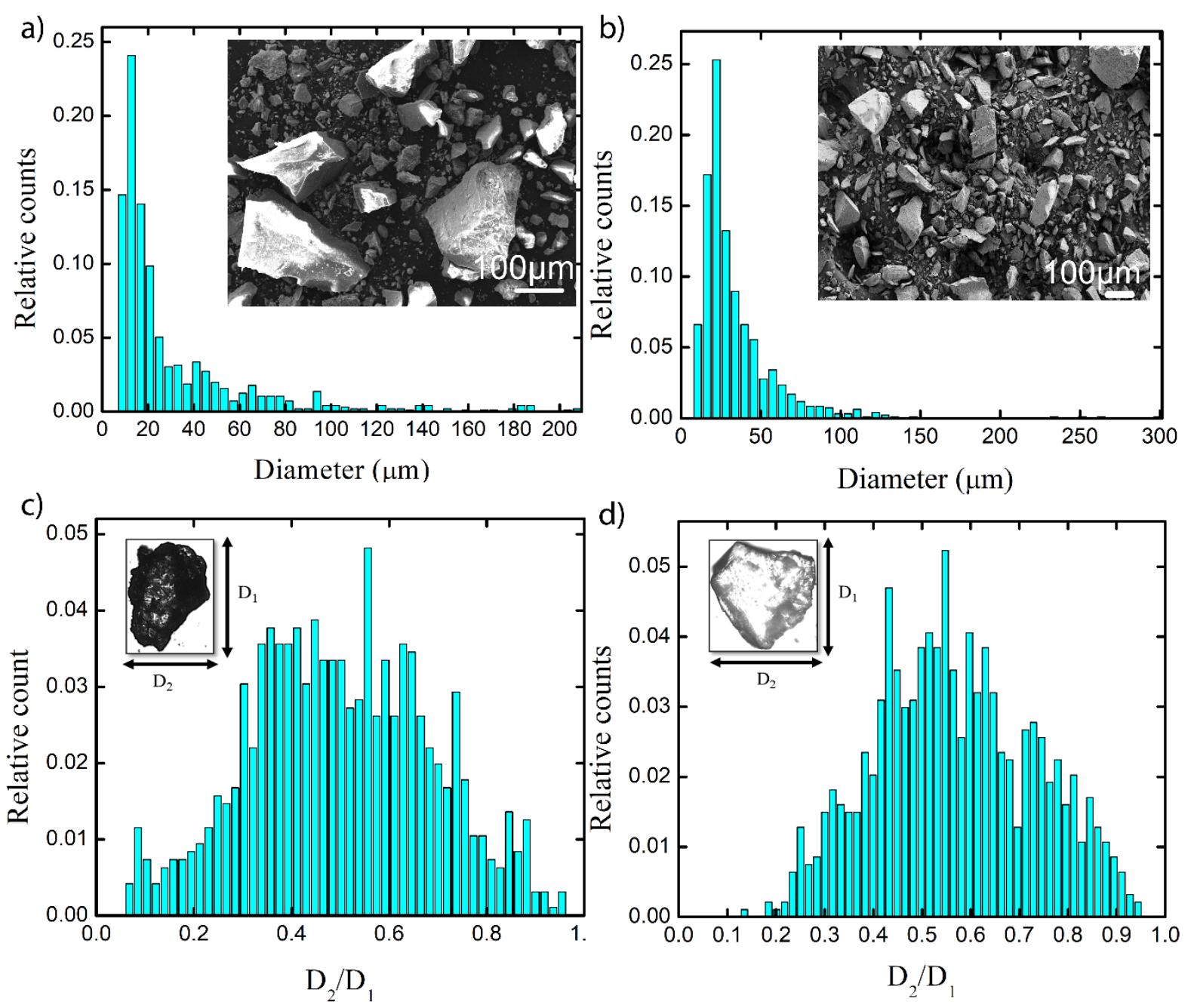

Fig:3: Characterization of raw MSS and LSS: Size distribution of a) MSS particles with an inset FESEM image of MSS and b). LSS particles with an inset FESEM image of LSS $c$ ) Aspect ratio for MSS particles and d) Aspect ratio for LSS particles. 

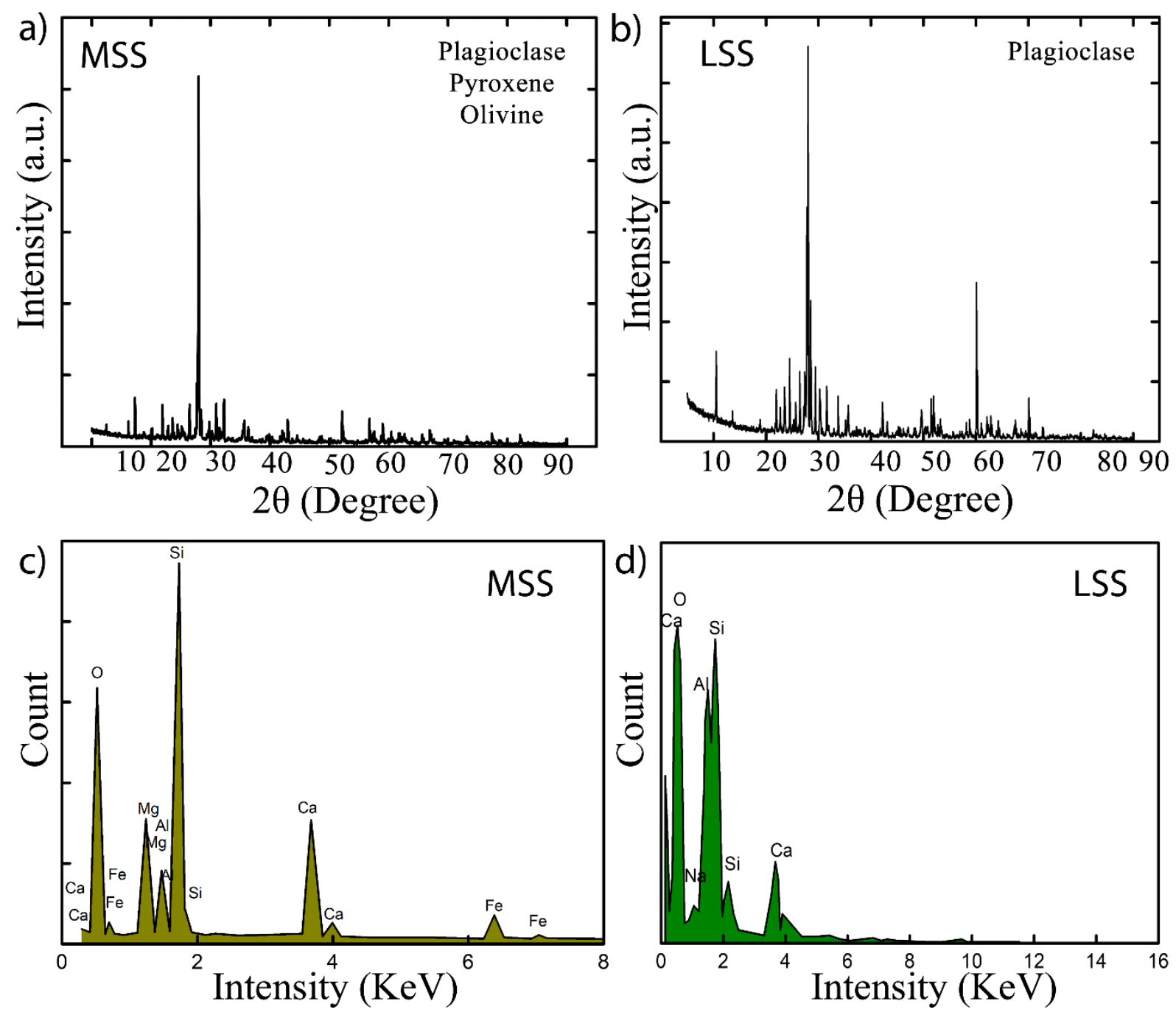

Fig:4: XRD pattern and EDS of raw soil simulants a) identified crystalline phases of MSS b) identified crystalline phases of LSS c) elemental mapping of selected location of MSS d) elemental mapping of selected location of LSS 
a)

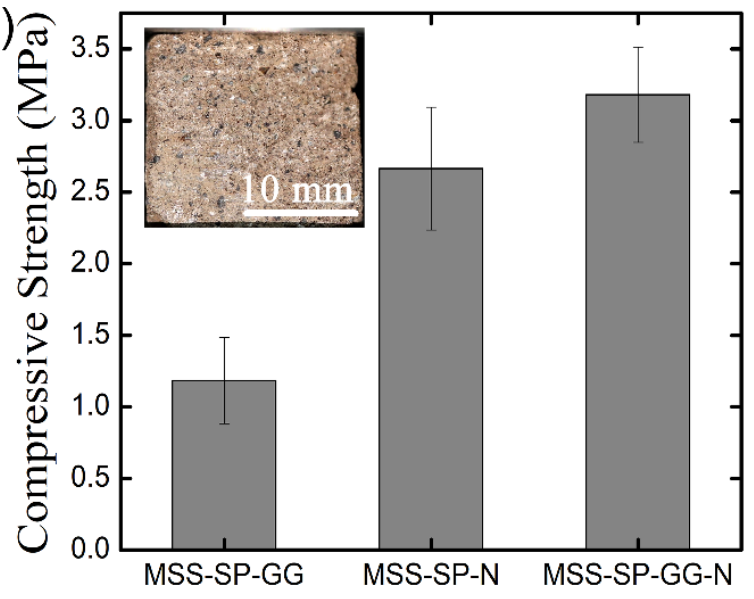

c)

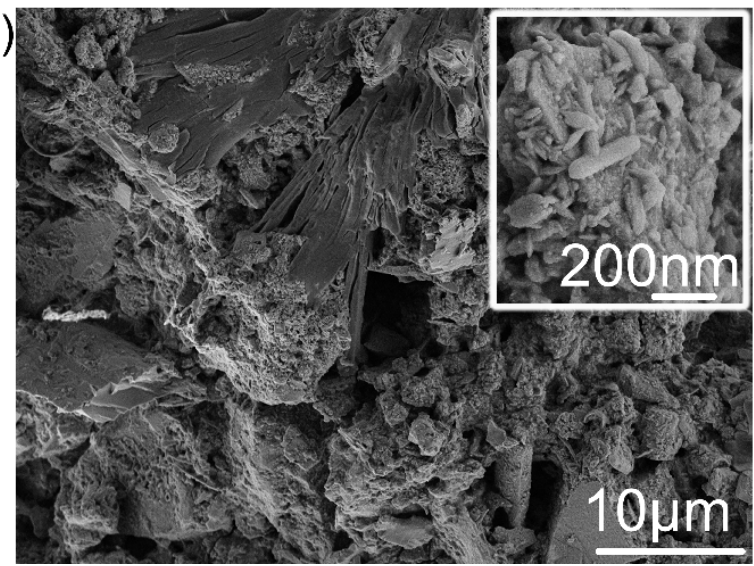

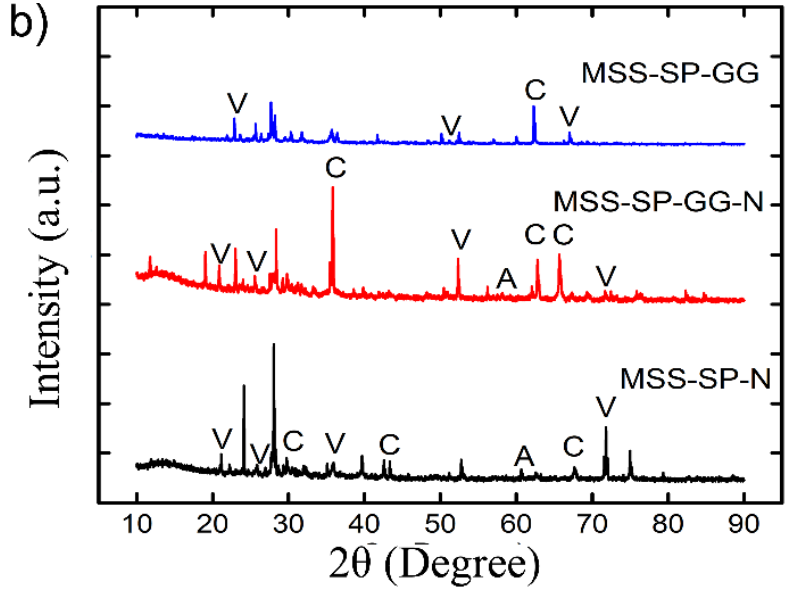

d)

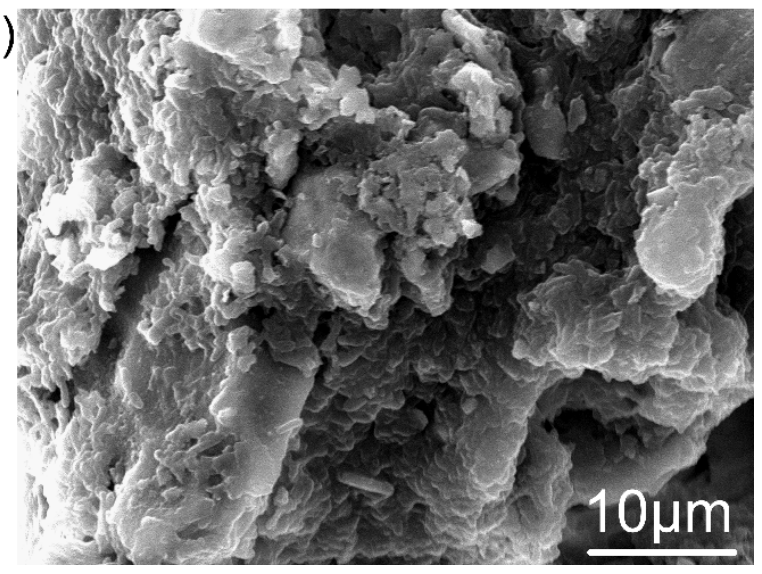

Fig: 5 a) Compressive strengths of martian bricks for different treatments with an inset image of cubical biconsolidated martian brick. b) XRD pattern of bioconsolidated martian bricks with different treatments (V-vaterite; C- calcite; A- argonite) c) showing SEM micrograph of martian bricks for MSS-SP-GG-N treatments. d) SEM micrograph for MSS-SP-GG treatment. 
a)

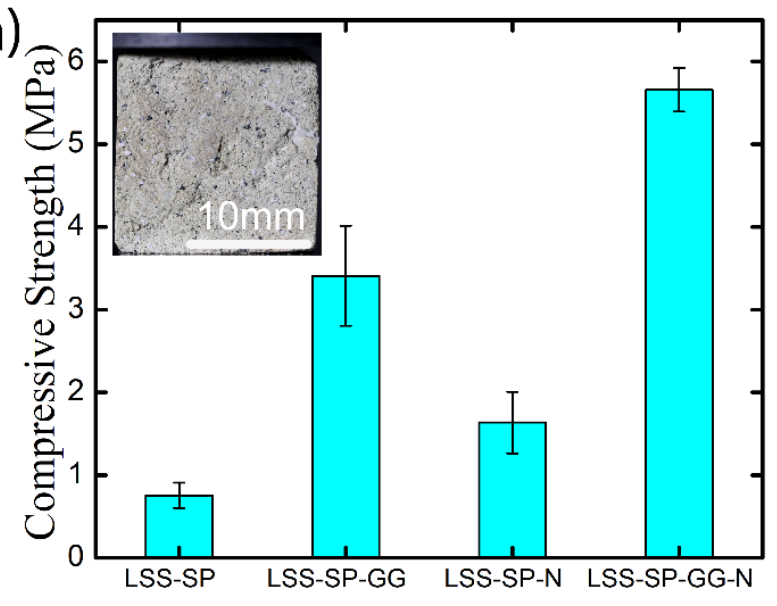

c)

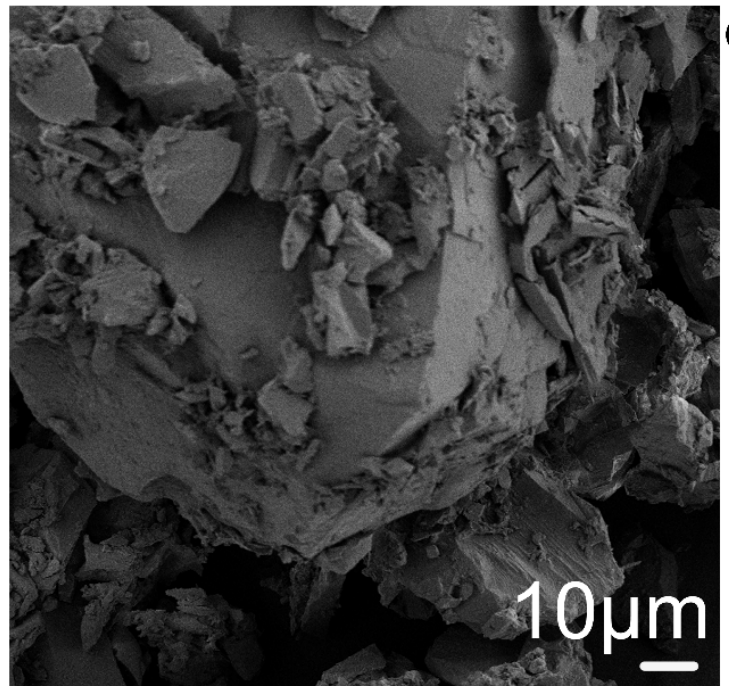

b)

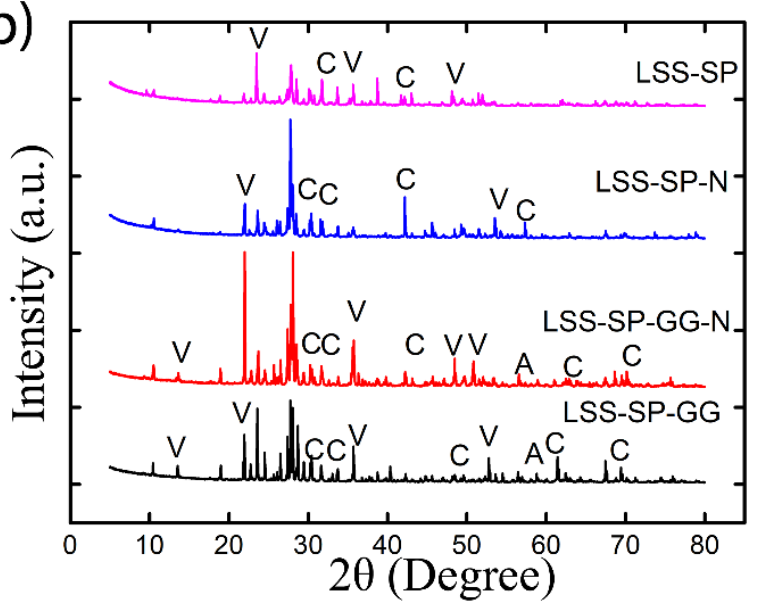

d)

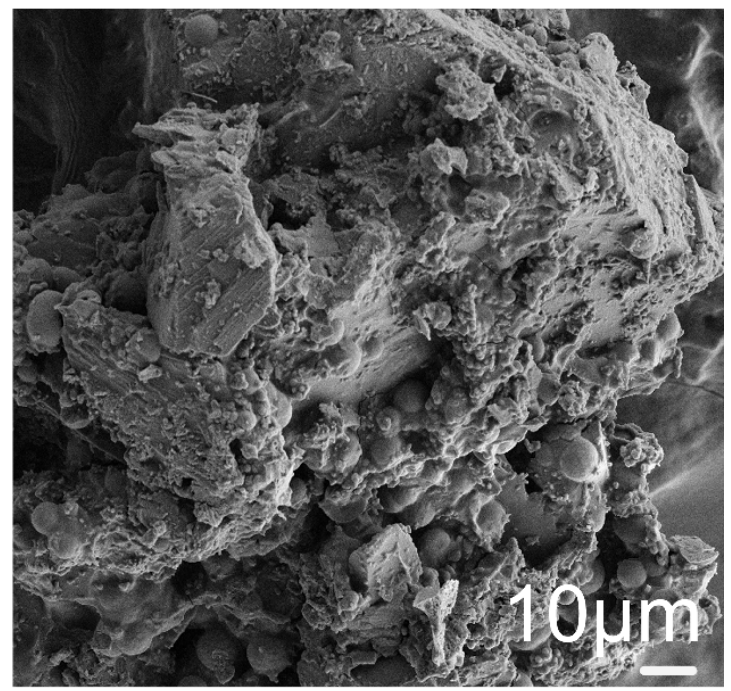

Fig: 6 a) Compressive strengths of martian bricks for different treatments with an inset image of cubical biconsolidated lunar brick b) XRD spectrum of consolidated lunar bricks with different treatments. (V - vaterite; C- calcite; A- argonite) c) showing SEM micrograph of lunar bricks with guar gum supplementation d) with guar gum and nickel chloride supplementation. 

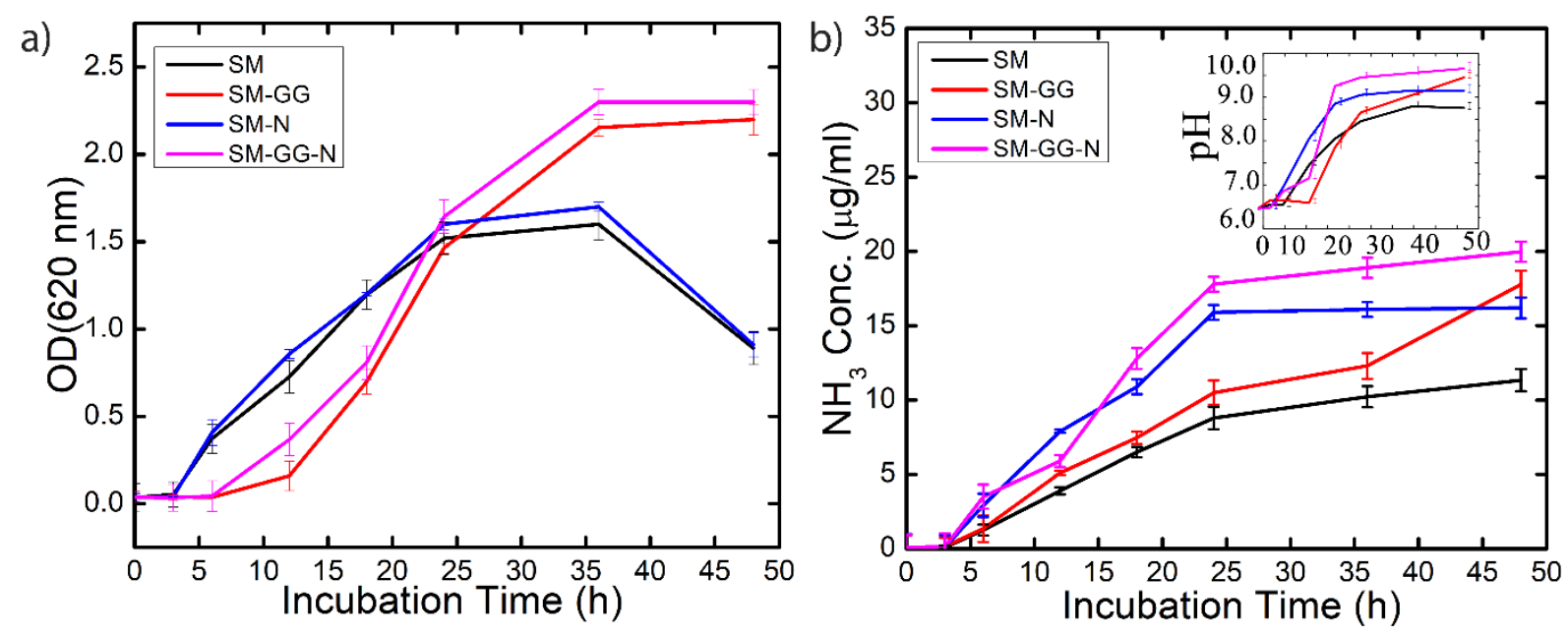

Fig: 7 Exploration of microbial physiology under flask condition with and without guar gum additive: (a) microbial growth curve (b) temporal evolution of $\mathrm{pH}$ (inset) and ammonium ion concentration in growth medium. Legend shows SM; media without any supplementation, SM-GG; SM media supplemented with $1 \%$ guar gum, SM-N; SM media with only $10 \mathrm{mM}$ Nickel chloride supplementation, SM-GG-N; SM media supplemented with $1 \%$ guar gum and $10 \mathrm{mM}$ Nickel chloride. S. pasteurii was used as inoculum in all cases. (Error bars represents the standard deviation of the data of three independent experiments). 